\title{
Exploring emotional expressions in e-word-of-mouth from online communities
}

Standing, Craig; Holzweber, Markus; Mattsson, Jan

Published in:

Information Processing \& Management

DOI:

10.1016/j.ipm.2016.01.001

Publication date:

2016

Document Version

Early version, also known as pre-print

Citation for published version (APA):

Standing, C., Holzweber, M., \& Mattsson, J. (2016). Exploring emotional expressions in e-word-of-mouth from online communities. Information Processing \& Management, 52(5), 721-732.

https://doi.org/10.1016/j.ipm.2016.01.001

\section{General rights}

Copyright and moral rights for the publications made accessible in the public portal are retained by the authors and/or other copyright owners and it is a condition of accessing publications that users recognise and abide by the legal requirements associated with these rights.

- Users may download and print one copy of any publication from the public portal for the purpose of private study or research.

- You may not further distribute the material or use it for any profit-making activity or commercial gain.

- You may freely distribute the URL identifying the publication in the public portal.

\section{Take down policy}

If you believe that this document breaches copyright please contact rucforsk@kb.dk providing details, and we will remove access to the work immediately and investigate your claim. 


\title{
The Contribution of Emotional Expressions in e-Word- of-Mouth
}

\begin{abstract}
Electronic word-of-mouth communication (eWOM) is an important force in building a digital marketplace. The study of eWOM has implications for how to build an online community through social media design, web communication and knowledge exchange. Innovative use of eWOM has significant benefits, especially for start-up firms. We focus on how users on the web communicate value related to online products. It is the premise of this paper that generating emotional value (E-value) in social media and networking sites (SMNS) is critical for the survival of new e-service ventures. Hence, by introducing a formal value theory as a coding scheme, we report a study on E-value in SMNS by analyzing how a Swedish start-up industrial design company attempted to build a global presence by creating followers on the web. The aim of the study was to investigate how the company's website design and communication affected eWOM. This was done by capturing a series of "emoticon and value expressions" generated by community members from three different e-communication campaigns (2011-2012) with changing website content Those members who expressed emotional value, often incorporating emoticons, displayed both shorter verbal expressions and reaction time. These value expressions, we suggest, are important aspects of eWOM and need to be actively taken into account. The study has implications for information management strategies through using eWOM.
\end{abstract}

\section{Introduction}

Word-of-Mouth (WOM) by definition comprises the customer's informal communications directed at other customers about the ownership, usage, or characteristics of particular goods and services and/or their sellers (de Matos and Rossi, 2008). It is often operationalized as referrals, which, however, is only one among many aspects of WOM. Referrals include what customers say to other customers and can take the form of implicit or explicit recommendation (Reichheld 2003). However, WOM has been found to include more than just recommendation. Much of what people say to each other is really about "what happened" (Söderlund and Mattsson 2011). WOM can therefore be an important source of information for people talking to others (Herr et al. 1991; Patterson 1998; Reichelt 2013). For example, consumers rely on WOM when 
selecting purchases that require a high involvement level (Arndt 1967; Brown and Reingen 1987; Rosenbaum-Elliot et al. 2011).

A web site and its online environment representation in video, photographs, diagrams or text descriptions can engender an emotional response, which in turn can lead to eWOM. We often find this in discussion amongst consumers pertaining to a product and is equivalent to a 'group think' syndrome that forms a legitimating and persuasive force for individuals. Emotions are related from a psychological perspective to feelings which can be thought of as perceived physical/mental sensations (Roseman, 1994).

Action tendencies are impulses or inclinations to respond with an action (Roseman, 1994). In the case of a product, a person typically makes a comparison and judgment on whether they like or dislike the product. Given the range of likely comparative products this is typically not done in a rational, cost/benefits manner as this would take too long but rather 'gut' feel or intuition is used to quickly assess whether the product has value or more value than other products (Damasio, 1992). The person can then decide to make a decision to voice an opinion (negative or positive) about the product on an emotional basis of how the product, if owned, would make the person feel (Zeelenberg, Nelissen, Breugelmans \& Peters, 2008). This can be communicated to others, through eWOM, in a form of emotional disclosure (Reynolds, Brewin \& Saxton, 2000). The intricacies of eWOM have become a topic of research in the information systems community in recent years (Saif, Zhu, Kiritchenko, \& Martin, 2014; Sun, Wang, Cheng, \& Fu, 2014; Verhagen, Nauta, \& Feldberg, 2013).

\section{Emotions in e-WOM}

The relative impact of emotion in eWOM is still vague (Yin, Bond \& Zhang, 2014), hence this paper investigates the eWOM process by comparing the e-WOM outcomes of three different website design and communication attempts (waves) made by a start-up design company during three time periods 2011-2012. We hypothesize that more prevalent emotional triggers on the website and communication may lead to more emotional eWOM generated by the online community.

Definitions of emotion differ but emotions are acute, related to evaluating non-trivial events or objects for relevance to one's preferences, and are different to moods which last longer. To assume the eWOM and product discussion is a purely rational process 
would be implausible. Participants are unlikely to invest the time and effort to mentally list the advantages and disadvantages, costs and benefits for all alternatives in each decision (Zeelenberg, et al. 2008). Emotions help us restrict the size of the consideration of alternatives and help focus the decision maker on certain options (Hanoch, 2001). Indeed, emotions assign value to objects (Gifford, 2002). Damasio (1992) argued that in the face of alternatives in non-trivial decision-making a bodily feeling or "gut feeling" results to draw attention to positive or negative outcomes associated with an alternative.

The content of what and how people communicate information and knowledge electronically, is the focus of this paper. As discussed above we define eWOM simply as "online interpersonal influence" (Litvin et al, 2008), or expressed differently; users or consumers peer to peer online communication related to products or services. We suggest that eWOM can have a number of potential benefits for firms and customers (Hennig-Thurau et al 2004) especially for community building on the web. eWOM has been shown to add value to advertising in that it influences early sales of a new product (Sussan, 2005). Getting early sales is critically important especially for start-up ventures on the web. Our focus in this paper is to investigate the effect of website design and web communication in a start-up venture on eWOM in relevant social and network sites. The research gap is therefore in identifying the contribution and characteristics of value expression in eWOM. We hypothesise that engaging and emotional design and communication on the web will be most effective in shaping eWOM.

There are similarities between WOM and eWOM in that both rely on trustworthy information, or referrals from familiar or third party sources that may have an impact on a person's decision-making or purchase intentions. However, there are also differences. In traditional WOM, although written communication was used, the emphasis has been on the spoken word which must be understood when the message is spoken, whereas in an online context eWOM seekers can read plenty of comments made by one or many eWOM givers delivered over time. Archival messages can still influence people.

We also see a distinction between the two types in eWOM's predominance of the written word. Traditional WOM can use body language in combination with the spoken word, which may frame the meaning of a message. As eWOM takes place online, users communicate with others by primarily using text-based messages (Hornik, Satchi, 
Cesareo, \& Pastore, 2015). Further, the Internet provides a cosmos of various communication channels that may create multiple communication flows between people that are not personally familiar with each other. eWOM therefore no longer occurs between a few people. A single user may post a message on a discussion board or on a commercial web site for many to see. Messages on Twitter or Facebook can stimulate eWOM communication that may generate great buzz online.

A further difference between eWOM and WOM is highlighted by Roed (2003) who showed, in an online learning context, that people who communicate through electronic channels appear to be more honest and forthcoming with their viewpoints and that they also disclose more personal information (Meuter et al. 2013). However, the latter authors also found that traditional WOM had more influence on behavioral intentions of recipients.

The importance of eWOM comes into play when people are socially independent or the level of commitment in decision-making is low. Nevertheless, eWOM is a powerful social act in which consumers use a broad range of rhetorical methods (Toder-Alon et al. 2013) when talking and interacting with others about goods, brands or services (Tan 2008; Groeger and Buttle 2014; Daugherty and Hoffman 2013).

The study of eWOM has important implications for the design and development of online environments and interactions with consumers and hence the information systems discipline. For example, particular design features can encourage or create a barrier to information and communication exchange. This has implications not only for the sale of products but also in relation to obtaining useful feedback that can be valuable in the design and co-creation of new products and services. In addition, understanding the value associated with knowledge about consumer perceptions can justify further investments in more elaborate methods such as social media mining.

As mentioned above, this study aims to capture "emotions and value expressions" from the discourse in social media outlets in order to gauge the effects on eWOM generated from different web-based campaigns of a start-up BETTER DESIGN. Hence a suitable theory pertaining to value and emotion is needed to analyse discourse on web. In the next section, therefore, we outline our choice of a formal theory of value (axiology) which incorporates emotion as well as two other dimensions of the human realm. 


\section{Value theory for coding eWOM}

eWOM often takes the form of short verbal expressions, comments or symbols (like emoticons). This makes it a challenge to unravel the "inherent content or meaning" of singular eWOM articulations as they, in some way, have to be coded in a practical and consistent way. In this research we introduce a new value coding approach to information management, based on the science of value (axiology). Because of space limitations, we will refrain from a comprehensive review of prior value theory drawn from philosophy. Instead we will, in some depth, outline the foundations for the formal value approach taken. Over the years, value concepts have traditionally been defined as an observable state in reality, without formally defining the content that constitutes value. (Rokeach, 1973), e.g., uses value concepts like "freedom", "national security" and "a comfortable life". This is an important shortcoming of the field. Holbrook (1996), an eminent value scholar, has made a comprehensive review of "consumer value" by drawing on axiology. He defines consumer value as "an interactive relativistic preference experience (ibid. p.1). As mentioned above, we also use axiology as foundation but with a formal approach to value. This is crucial when coding text online as formal types of value can then be extracted from the content of online expressions. Hartman's (1967) value concept is, to our knowledge, the only formal one and in line with the value definition of Holbrook (1996). The former defines value of a thing as the degree of fulfillment (in Holbrook's terminology "relativistic") of the intension of its concept (Holbrook's terminology "interactive preference"). Hence, very similar definitions, but as we shall see, only Hartman's definition is formal. Let us explain why. By intension Hartman (1967) meant the norm of the person who values something, or content of goodness criteria for a concept already existing mentally prior to valuation. This norm is compared (at the moment of valuation) to what is actually perceived of the concept. The more of these goodness criteria that are seen to be present, the more value is assigned. Value is therefore not something inherent in the thing but the relation between the amount of goodness criteria (ex ante) and what is perceived of these criteria in a thing or situation (ex post). It consists of the mental comparison (or rather a kind of cognitive fusion) between the intension and the perceived extension of a concept. The part of the intension (ex ante), which is fulfilled (ex post), is defined as positive value and the remaining part (non-fulfilled) negative value. We can write it as a formal relation as follows: Value $=$ Intension - Extension or in simpler terms, the mental fusion between Intension and Extension of something. Hence, the Intension of a thing is the formal concept (ex ante) that is compared with another formal concept (ex post) to 
define the value of that thing. There are different ways to "fill" the Intension and Extension concepts to create a typology of formal values.

Hartman (1967)differentiates between three value dimensions: the intrinsic (which we term emotional= E), extrinsic (here termed practical=P) and systemic (here termed logical=L). The reason Mattsson (1990), who was the first to apply the theory in management, used these different labels was to facilitate their everyday comprehension. These dimensions are construed to be different modes of perceiving reality. Differentiating these dimensions by their degree of richness the emotional dimension is defined to be far greater than the practical, which in turn is greater than the logical (Hartman 1967). Simply speaking, the emotional dimension is said to contain an infinite number of properties, each a continuum and therefore the richest one. The practical dimension also contains an infinite number of properties but each and every one of them is considered denumerable (discrete). It is consequently less rich. The logical dimension, finally, only has a finite number of denumerable properties. It has the least degree of richness. Hence richness of a dimension refers to the number and complexity of its properties. Nevertheless, the three dimensions can be fused together into what is termed value types, the categories of our coding scheme.

The formal expression of value suggested above, namely Value =Intension - Extension makes it possible to define nine different combinations of value dimensions. Both the intension (which is defined as "the internal content of a concept") and the extension (external content of a concept) part of the definition can be emotional, practical, and logical. Consequently, we have the following possibilities (denoting $\mathrm{E}=$ emotional; $\mathrm{P}=$ practical and L= logical); E-E, E-P, E-L, P-E, P-P, P-L, L-E, L-P and L-L. Each one of these value types can be seen as a positive (denoted by + between the letters such as E+E) or a negative value (denoted by a - between the letters such as $L-L$ ), and therefore, we can actually define 18 types, nine positive and nine negative values. The first letter refers to the dimension of the intension of a concept and the second letter to the dimension of the extension of the concept. The negative value types are symmetrically ordered in reverse (Mattsson, 1990, p. 116-121). The crux of this ordering of value types is that certain Evalues (those with the first letter $\mathrm{E}$ and ranked 1-3 are the most rich and important ones. Hence, by using this simple ordering of value types we can easily discriminate between important and less important value content in eWOM. By combining all Evalues we simply add up all types with the combination E-X and X-E (positive or negative E-E; E-P E-L, P-E and L-E). Similarly by combining all types with a P-dimension 
(positive and negative P-X and X-P) we get a measure of P-values. Finally, L-values are those with the combination positive or negative L-X or X-L. In the following we will simplify the analysis of coding results by including only $\mathrm{E}, \mathrm{P}$ and L-values defined in a narrow way as those types with the intension $\mathrm{E}, \mathrm{P}$ and $\mathrm{L}$ respectively. E-values will be those ranked 1-3, P-values those ranked 4-6 and L-values those ranked 7-9. The reason for this limitation is the nature of the text we code, i.e. often short expressions, sometimes with symbols and signs, and without completed sentences. In other words, we have to deal with highly dense, expressive and impromptu remarks.

Hartman has further suggested that these 18 value types can be ordered (as above) as to their richness (importance) in his value instrument (Hartman, 1973). Early research on this instrument (called the Hartman Value Profile) and its underlying theory has verified the value dimensions (Elliott, 1969) and its empirical validity (Lohman, 1968; Austin and Garwood, 1977). Davis (1978) goes further and finds the theory formally true, that is that all values can be accounted for, and that it allows us to order value experiences. Moore (1973) also finds that the value dimensions can serve as a basis for a universal and ethical theory. Since the Mattsson (1990) attempt to apply and validate Hartman's value theory a number of marketing applications have further validated the Hartman approach to values (de Ruyter et al., 1997; Lemmink and Mattsson, 1996; 2002; Danaher and Mattsson, 1998; Barnes and Mattsson 2008). Consequently, it has been possible to logically confirm the Hartman value hierarchy and its empirical relevance for business. Because of its prior usefulness in management research we will code online WOM text in terms of $\mathrm{E}, \mathrm{P}$ and $\mathrm{L}$ value. When presenting results from the coded expressions values will be denoted in brackets, such as (E) values, the focus of this research.

\section{Research Method}

Three design enthusiasts and former Nokia employees, all graduates from a leading Swedish design school, and one business school graduate, started a company to offer 'better' design concepts and 'better' designed products for the European market. The small group of founders named their first company 'BETTER-DESIGN'. Their desire was to make 'better' products for a 'better' world. The underlying meaning of 'better' still aims at being more 'green', and more 'sustainable', and also being more 'transparent' when sourcing material for their designed products. Practically, the idea was to use local or regional sources that could deliver materials to be recycled, or easily repaired, instead of being replaced or substituted by new products. All three designers were frustrated that they could not live up to this design philosophy when working for a 
multinational corporation such as Nokia. Rather, they were looking for more adventurous, unique, and sustainable design contributions. Consequently, they simultaneously quit their jobs at Nokia to start something new.

\section{Data collection}

Case study research is widely considered as an appropriate means of examining social phenomena within a specific context without control or manipulation of the behaviours (Stake 1995; Yin 2012). We decided on a single case because an in-depth single case enables rich data gathering on contextual issues that are relevant in understanding the WOM phenomenon. We selected BETTER-DESIGN, formed as a Swedish company with base in Stockholm as the case company for several reasons. Firstly, a start-up has no or at least fewer preconceived perceptions to manage in relation to their branding and product offerings. Secondly, this particular start-up venture used social e-technologies when communicating with people and potential customers. We followed their decisionmaking processes, communication and marketing activities, their patterns of social media marketing and knowledge work and drew insights from data covering two years (2011-2012) We followed their blogs and communication online during three different website campaigns (waves). Additionally, we used text-based comments on various interior design, style and technology and/or gadgets oriented web sites to collect data. We copied verbatim user contributed text, aligned with our earlier definition of eWOM as open communication on the Web, from the company's own Facebook page, their own Kickstarter web pages, and supplementary web pages such as 'appartmenttherapy.com', 'boingboing.net', 'gizmodo.com', 'hypebeast.com', 'geek.com', 'engadgets.com', 'blessthisstuff.com', digitaltrends.com, 'geekandhype.com', 'cnet.com', and 'wired.com'.

There are various analytical methods one can use when investigating comments, referrals, and what is termed discussion threads. Although every comment was included in the study we did not perform a discourse analysis of each discussion thread to explore relationships from a network perspective. Instead we limited our data sample to only include different value content in individual comments or articulations.

\section{Data analysis of text measures}

We built our sample on comments that included full information about (1) time, (2) date, and (3) user name or alias to identify multi-comments. In a first step we put all comments from the mentioned web sites, which addressed our product, into spread sheet columns, each of which included; data source, time stamp, and user alias. In the 
next step, two authors coded the data as to the three types of value namely E, P and L. The coding displayed similar outcomes with a reasonable correspondence. We quantified each single value result as ' 1 '. Missing value code cells were left empty.

In a next step, the extracted Unix based time-stamp number was translated into a week, day and hourly-based time system for analysis. We measured the volume of the variable 'text volume' by using a function in the software package MS-Excel. The syntax 'LEN(text)' was used to measure a string value (text based comment) which corresponded to text length. We counted spaces as characters. The length variable ranged from 3 characters for a simple 'yes', to 1103 characters for the longest text comment. Finally, we used the statistical package SPSS version 20 for analysing the pattern of values in the data. Our data resulted in 174 useful comments. As mentioned above we used two variables, 'text volume' and 'response time' as surrogate measures of impact to explore the characteristics of value expressions in the eWOM comments. This set will now be explored as to how value expressions emerged over time.

Note, however, that we only used text generated by active users and followers of a few social media platforms. To focus text sampling of relevant media sources we chose a unique design product (loud speaker) from BETTER DESIGN and investigated the company's customer base of 490 online customers. Overall two authors manually coded the comments as to their inherent (E), (P) and (L) values. Discrepancies (around $25 \%$ ) in coding were resolved by discussion. As mentioned, because of the very special character of texts such as the inclusion of so-called emoticons and other exclamation signs we concentrated the coding on value intension (first letter of the value type), which reveals more of the mental state of the author of the text. An emoticon (the word "emotion" merged with "icon") is a pictorial representation of a facial expression to signal the temper of a text author's message and normally expresses the feelings or moods of the sender. These emoticons such as the common "smiley (-)" now play a significant role in social media (Walther and D'Addario 2001). We have therefore extended our text analysis to include these emoticons as important carriers and tenors of value.

A number of examples of the coding are provided below. Emotional value was assigned to a comment when the text included strong emotional symbols like smileys, exclamations marks, and other emotional expressions. Typical positive examples are: ' $I$ love it!!!' (E), or 'Nice!!' (E), or 'Pretty awesome!' (E). 
Practical value found in texts dealt with physical features of the loud speaker such as this comment: Ugh. (P) Wouldn't it be better to encase the in some pretty-looking wood or something than to have their guts all splayed out? (P) Another positive exemplar of $\mathrm{P}$ value was: I wouldn't call it invisible, more like see through, but still nice to have. (P)

Logical value in comments, finally, just paid attention to factual information. One example of an abstract nature was: Thanks! Noted for future reference (; (L). A more comprehensive version of the cognitive L-dimension was: Good to know!(L) I need new speakers. Ok I want new speakers. I just need to somehow make my girlfriend think we need them... (L)

\section{Results}

\section{Categorization of customers}

We first give a descriptive background of the customers of BETTER-DESIGN's audiophile project. It has successfully raised its funding goal by 140 per cent. 490 backers funded the project with starting pledges from USD1 up to USD499. More than half $(59.2 \%)$ of BETTER-DESIGN's customers were from the United States of America or Canada, more than a quarter $(26.2 \%)$ are European based, 10 per cent are from Australia or New Zealand and about 4.2 per cent are located in Asian, African, or South American countries.

Segmenting customers from Kickstarter data allowed for three categories: (a) high-level, (b) mid-level and (c) low level contributors. We identified the categories by analysing groupings in the entire data and through discussion amongst the researchers and the commercial manager of the case study firm. The high-level group included 17 backers (3.5\%), who backed more than 100 projects on Kickstarter. A single backer backed 767 projects. Other high-volume backers have backed $631,513,442$, or 301 , and some have significantly less. This group of high level backers is interested in many different themes such as music, design, art, festivals, movies, and rare but stylish gadgets. We may term such consumers design 'collectors'.

The mid-level category account for a quarter of BETTER-DESIGN's customers. This group (24.5\%) backed between 10 and 99 projects. The nature of their backed-project portfolio was multidimensional. Music, art, technical gadgets, computer accessories, and other design-oriented items were among their buying basket. 
The low-level group funded BETTER-DESIGN's audiophile project. They are music enthusiasts. This audiophile and music 'lover' group (72\%) backed up to 9 projects on Kickstarter. Hence, the low level backers are BETTER-DESIGN's core customer group. Based on their individual buying baskets, we can term these customers music and design 'professionals'. They can be characterized as young, trendy music lovers, who are digitally consumption-oriented. This group is also interested in green issues about sustainability when sourcing raw materials for processing and manufacturing. As noted above, a typical BETTER-DESIGN customer is a low level backer, sensible towards the product offering in terms of ecology and sustainability, and mostly located in the US. This customer group looks for premium and authentic audiophile products that offer a combination of sustainable design and high quality music consumption.

eWOM in three web-communication campaigns for the audiophile project

Findings showed that eWOM concerning this product included much (E) value. As will be discussed below this has helped the founders of BETTER-DESIGN to fully understand WOM's impact on consumers on the web and, consequently, the importance of actively managing eWOM.

Managing eWOM, we suggest, incorporates the understanding of which dimensions of value that are most important to community building. Therefore, we carry out an eWOM analysis with the aim to pinpoint the impact of different e-sources. As noted above in the literature section, eWOM can prompt a consumer to reflect on a brand, or a product in a way that traditional advertising cannot. While eWOM has different degrees of influence on consumers it is nevertheless important to get a better understanding of the factors that sustain the process of 'talking'. In the next section we briefly outline the process of BETTER-DESIGN's experiential communication with the audiophile project.

The operative activities of the project started in 2010 with a flexible and lean online communication concept. In early 2011, at the first wave of online messages the overall responsiveness was weak. The first online campaign triggered few (P) and (L) values in the online communication. BETTER DESIGN now intended to build its campaign around emotional positioning, but we found that online users tended to generate buzz mostly about functional (P) messages. The first online campaign could not ignite eWOM communication. 
After this learning-experience BETTER-DESIGN launched an improved second online campaign, using more visual online material, messages, and press releases. More and detailed information about the product was posted on social media channels. It generated more and better online communication in terms of eWOM. (P) and (L) valuedriven communication about functional aspects were triggered. Again, however, the campaign generated very few (E) values. Online communication of the second wave comprised more information about BETTER-DESIGN's identity. This may have been necessary to bolster online trust for BETTER-DESIGN. Community members must really believe that the company knows the product in detail. However, we could not identify a homogenous group of users who were influential through their comments incorporating E values. Audiophile users might influence music enthusiasts but not consumers who shop for interior belongings or tech-gadgets. In sum, none of the two communication campaigns could create a strong enough buzz that could start WOM on the web.

BETTER-DESIGN now asked business friends for mentoring and support. Two closely related consulting firms were asked to work on a plan for a third online campaign. This time, BETTER-DESIGN focused on emotional triggers. The new campaign started online in January 2012. It lasted until summer and faded in October 2012. It was successful in terms of eWOM and (E) value comments. Findings showed that the e-environment where eWOM circulates is key to the power of communication. The founders of the firm believe authenticity and telling the truth are necessary communication approaches in social media. As illustrated in figure 1, coded (E) value oriented communication in eWOM (that is added value types with the intension E, namely E-E. E-P and E-L) was much more numerous (red dots) compared to coded $\mathrm{P}$ and $\mathrm{L}$ value expressions. The emotional triggers included in the BETTER-DESIGN communication were different such as: strong emotional expressions, artistic visual appeals, and authentic story telling. As can be seen in figure 1 this generated eWOM over a 10 week period, which really supported community building on the web. 


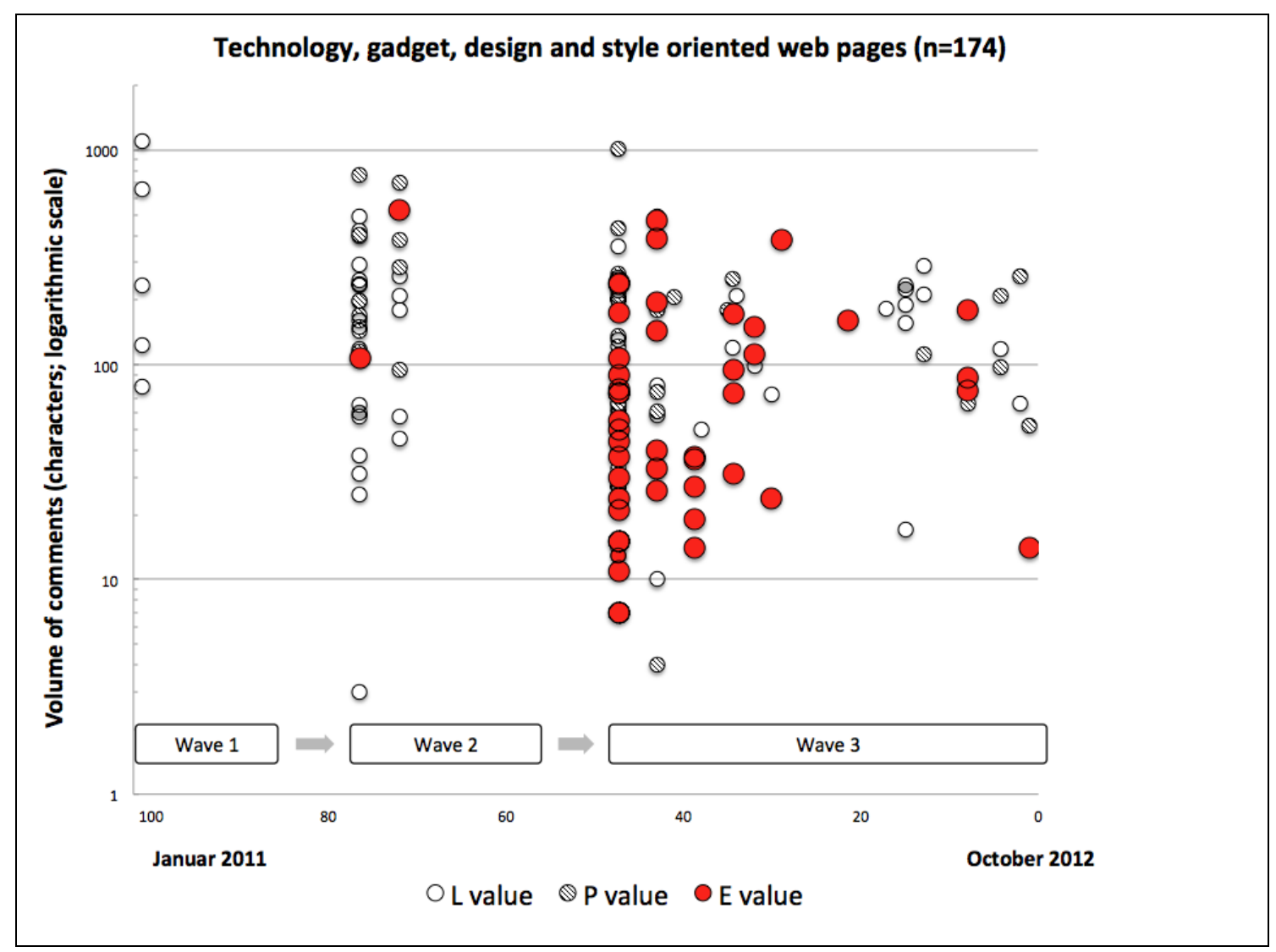

Figure 1: Value related online comments $(\mathrm{N}=174)$

Analysing text length of value comments

As mentioned above a second variable in focus for quantitative analysis was the length of comments (entire sample $\mathrm{N}=174$ ) for the three groups of $\mathrm{E}, \mathrm{P}$ and $\mathrm{L}$. The result of an 'one factor' analysis of variance revealed a significant effect for the volume of text manipulation on 'emotional' value, $\mathrm{F}(1,172)=5.739, \mathrm{p}<0.05$. Mean scores for the text volume (amount of characters) of online comments were 97.391 ( $S D=116.124$ ) for 'emotional' comments and 165.757 (SD=180.402) for practical or logical comments. The range varies from 518 characters at the 'emotional' group to 1,110 characters at the 'practical' and 'logical' group.

Online users act differently, depending on their value orientation as depicted by eWOM. Those users who browsed the web pages and entered comments that are coded 'emotional' tended to enter shorter comments than those who entered 'practical' or 'logical' comments. Figure 2 illustrates this finding by comparing text volume of groups expressing 'emotional' and 'practical and logical'. 


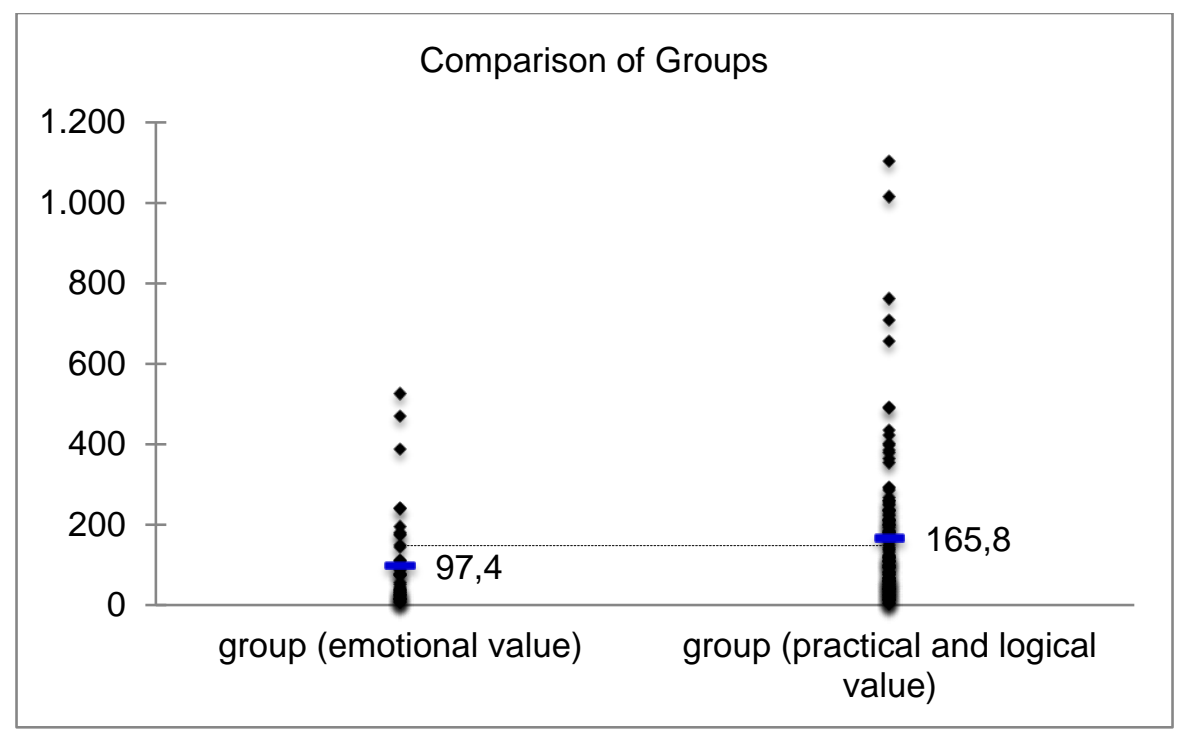

Figure 2: Comparison of groups: Text volume $(\mathrm{N}=174)$

\section{Analysing response time}

The result of a univariate analysis of variance revealed a significant effect for the response time, $F(1,172)=5.590, p<0.05$. Mean scores for the response time (full period of 700 days) of online comments were 419.311 (SD=95.683) for 'emotional' comments and 356.777 (SD=169.751) for practical or logical comments. The overall minimum response time for (E) value users was 171 days (third wave) and less than a day for $(\mathrm{P}, \mathrm{L})$ value users (first wave). Due to the independent nature of the single campaigns the overall results of the variable 'response time' are skewed. It mirrors heavily the experimental approach of BETTER-DESIGN's first and second campaign. Therefore, we decided to focus on the third wave only and perform the same tests again. The next parts, therefore, only present results from the third campaign as it may increase the understanding of how and what activates eWOM.

\section{Analysing the third wave}

The third communication campaign started in January 2012. We now use a sub-sample of $\mathrm{N}=127$ online comments. We performed an ANOVA to investigate the effects of emotional value. We compared the means of both groups using an independent samples t-test first on text volume and subsequently on response time.

Text volume: The result of a univariate analysis of variance revealed a significant effect for high or low text volume, $F(1,125)=5.082, p<0.05$. Mean scores for the text volume (amount of characters) of online comments were 79.409 (SD=67.843) for 'emotional' comments and $130.373(\mathrm{SD}=141.379)$ for practical or logical comments. The range 
varies from 233 characters at the 'emotional' group to 1,110 characters at the 'practical' and 'logical' group.

Response time: The result of a univariate analysis of variance revealed a significant effect for response time $F(1,125)=4.656, p<0.05$. Mean scores for the text volume (amount of characters) of online comments were 47.171 ( $\mathrm{SD}=73.222$ ) for 'emotional' comments and 83.298 (SD=97.350) for practical or logical comments. The minimum response time for (E) value users is less than a day compared to 2 days for $(P, L)$ value users. Hence, (E) value users are quicker in taking up the word and communicating online. Their voice cuts through social media channels quicker than (P) or (L) value users.

\section{Discussion}

In summarising our findings, we found that users expressing (E) value are quicker in taking-up and spreading the word to their community. Also, it seems as though (E) value users express their opinions more directly (shorter more succinct responses). BETTERDESIGN focused on meaningful pictures as emotional triggers at their third wave of press releases and in online information.

Our findings may be interpreted as follows: eWOM is impacted by strong visual and artistic effects. (E) value users' responsiveness is most likely also different compared to $(\mathrm{P})$ or $(\mathrm{L})$ value users. (E) value-oriented community members seemed to be impressed by the given information and express their WOM quicker and in a more concise way. The reasons for this can theoretically explained as follows. Individual value expressions are the result of a mental process. Emotions in particular are a response to a physical artefact (web site feature or eWOM statement) and are intuitively created on the spur of the moment (Damasio, 1992). With logical and practical expressions more time is taken because the individual considers a range of alternatives and assesses the pros and cons of each one. The shorter expression found in emotional responses can be explained by how individuals might feel to own the product (Zeelenberg, et al. 2008). Simply, an emotional response only requires a short expression of feelings whereas logical and practical statements typically require more detailed explanation in line with that style of thought. As it is important for a start-up company to build a market quickly this finding has strategic implications. Therefore, (E) value users can be of great help in encouraging eWOM by disseminating opinions and posting referrals online through social networks. This is inline with Fang (2014) who found that affective stimuli and subsequent arousal contribute to eWOM adoption. 
Implications of the study

Innovative use of eWOM has a number of potential benefits for information management in firms. For example, information managers can engage better with consumers if they understand how to facilitate more informative discussion, both with consumers and the firm and consumers with other consumers. This study has implications for innovative system design in three main areas: for the design and development of online and social media environments, for information and knowledge sharing between consumers and the process of social media mining.

It is evident from our research that communication takes different forms, specifically in terms of expressing value associated with a product or service. However, it is still unclear how effectively ICT systems can support these communication forms (Standing \& Kiniti, 2011). Indeed, there is conflicting evidence in the research literature in relation to, for example, electronic media's capability to express emotion. Some argue that emotional communication online and offline is surprisingly similar since people may use language (text) more explicitly online when there is a lack of visual cues that are typical of face-to-face communication (Derks, Fischer \& Bos, 1998), although this suggests a communication adaption style to compensate for the restricted medium. It is also recognised in the literature that online communication environments, especially textbased channels, lack richness of expression capability (Willis \& Jones, 2012) and therefore developers should strive to support communicative cues to better facilitate expression and interpretation of emotion. Hence, we suggest that those organisations prepared to develop different forms of emotional value expression in their online communities and social media use can potentially gain an advantage.

Developers should be aware how different communication tools can express emotional, practical and logical values. This appears especially true for mobile communication given the preference of using this device to share personal data (Willis \& Jones, 2008). Building in L values to an online system could involve making explicit the rules and norms of the environment. $\mathrm{P}$ values could be hard code designed as alternatives, with the emphasis being on the functionality of a product or service and the fit between product and consumer. Functionality with most products or services, or environments can be defined by a restricted set of options on a menu for example. E values finally could be supported by diverse communication options such as free style expression, emoticons, pictures, photographs, video, audio and text. Quick and easy online methods 
of sharing emotions should be available since those exposed to the social sharing of an emotion commonly share that episode with others (Christophe \& Rime, 1997). In addition, optimal group size is worth considering since smaller groups typically engage in more emotional communication and larger groups are less inclined to share and respond to emotional reports of others (Willis \& Jones, 2008). In other words, our research suggests that there needs to be a matching of product, customer and online communication environment.

An interesting question in this area of $E$ value is what is its role in information and knowledge sharing? E value can be an important community influencer in a number of ways. Emotion signifies intention, such as an intention to buy a product, and also may motivate someone to initiate communication that may in turn lead to information and knowledge sharing. Research by Ma and Agarwal (2007) has shown that particular IT artefacts in online forums such as instant messenger, chat rooms, "who is online" features, "who is doing what" features can facilitate greater information and knowledge sharing. Individuals who felt community members verified their identities personally and socially were more likely to participate in knowledge sharing and creation.

Group size has implications for knowledge sharing. It is argued that people are less committed to larger groups and contribute less to them (Karau \& Williams, 1993). Hence, if firms wish to stimulate product discussion then forum size can be an issue to encourage honest and passionate feedback. Too many people often reduces the depth and quality of responses but too few participants does not provide the continuity of dialogue to make people return (Markus, 1987).

Group identity influences the behaviour and knowledge shared. Socially bonded participants have stronger ties than professional groups and are more likely to share deeper knowledge. For example health groups are often bond-based, while politics groups tend to be topic-based (Arguello, et al., 2006).

There has been a growth in mining social media contributions for sentiment analysis in relation to a product or service. This can be defined as the automatic detection of opinions from free text. Our study is part of this research trend but is distinctive because it examines types of value expression in user responses. However, related research has implications for value expression analysis. For example, research on emotional comments in MySpace has shown that females are more likely to use positive emotion 
(Thelwall \& Wilkinson, \& Uppal, 2010). Twitter feed has been analysed to detect changes in public mood and sentiment and can be used as a predictive tool (Bollen, Pepe \& Mao, 2010). Hence, it is possible that 'mood' responses to a product may be used to determine the success of a product or service.

\section{Limitations to the study}

There are a number of limitations to this study. First, we focussed data collection on one company, BETTER DESIGN, and only on the audiophile project and the unique design product (loud speaker). This is clearly a narrow approach to data collection. Second, we investigated the company's customer base of 490 online customers and simply copied verbatim text from the start-up's own web blog and from a handful of other web sites such as 'apartmenttherapy.com', 'boingboing.net', 'gizmodo.com', 'hypebeast.com', and 'wired.com'. Hence, we may have missed discussion and data in other relevant echannels.

Third, coding of value is always tricky, especially when dealing with jargon and the "condensed" (such as emoticons) expressions that international users generate on the web. Nevertheless, two authors coded the data independently as to the three types of value namely $\mathrm{E}, \mathrm{P}$ and $\mathrm{L}$, and then compared outcomes. The rate of agreement was acceptable (around $75 \%$ of codes matched). All disagreements between the two coders were resolved to allow for the inclusion of all relevant comments. Fourth, we only used simple statistical tests on the categorical data that was generated. Hence, our patterns of value distribution over the different phases of communication must be seen as tentative, awaiting further exploration and testing.

\section{Conclusion}

Social media use by organisations has come in for some criticism in the press for lacking relevance and purpose. This study demonstrates that more detailed analysis of user group comments can be extremely valuable to the firm and eventually the consumer base as products are refined and improved by this method. The theoretical basis of our study in terms of the contribution of emotions in eWOM provides a firm basis for future research in this area. The value dimensions embedded in this eWOM discourse we have argued have many implications for online communication, social media design and analysis, and online community development. The more firms understand the nature of the crowd the more they will be able to harness its potential. Innovative analysis of 
eWOM can be used to refine products and services and create a demand in user communities.

Future research could consider replicating the study across other organisations and other types of products. It could also consider gender differences in the types of value responses and the forum size in terms of number of participants as it is thought that responses change in smaller groups. Longitudinal research could add insight on whether positive emotional responses are predictors of sales. Further, a finer grained analysis could examine the extent to which types of responses (E, L, P) encouraged others to respond and the nature of those responses.

\section{References}

Arguello, J., Butler, B., Joyce, L., Kraut, R., Ling, K., Rosé, C., and Wang, X. (2006). Talk to Me: Foundations of Successful Individual-Group Interactions in Online Communities. In Proceedings of the SIGCHI conference on Human Factors in computing systems (CHI'06).

Arndt, J. (1967), "Role of Product-Related Conversations in the Diffusion of a New Product." Journal of Marketing Research 4 (3) (August 1): 291-295. articulate themselves on the internet? Journal of Interactive Marketing, 18

Austin, J. J., and Garwood, B. A. (1977), “The relationship of the Hartman Value Profile (HVP), Rokeach Value Survey (RVS), Allport-Vernon-Lindzey Study of Values (AVL) and Kohlberg's Theory of Moral Development (KMD): a series of axiometric studies", Proceedings at the 1977 National Association of School Psychologists Convention, Cincinnati.

Barnes, S., and Mattsson, J., (2008), Brand Value in Virtual Worlds: An Axiological Approach, Journal of Electronic Commerce Research, vol. 9, no. 3, pp. 195-206.

Bollen, J., A. Pepe, and Mao, H. (2010), “Modeling public mood and emotion: Twitter sentiment and socio-economic phenomena," in Proc. of WWW 2010 Conference.

Brown, J.J., and Reingen, P.H. (1987), “Social Ties and Word-of-Mouth Referral Behavior." Journal of Consumer Research 14 (3) (December 1): 350-362.

Christophe, V., and Rime, B. (1997), Exposure to the social sharing of emotion: Emotional impact, listener responses and secondary social sharing. European Journal of Social Psychology, 27, 37-54.

Damasio, A. Descartes' Error: Emotion, Reason and the Human Brain. New York: G. P. Punam's Sons. 
Danaher, P., and Mattsson, J. (1998), “A comparison of service delivery processes of different complexity", International Journal of Service Industry Management, Vol. 9, No. 1, pp. 48-63.

Daugherty, T., and Hoffman, E. (2014), "eWOM and the importance of capturing consumer attention within social media", Journal of Marketing Communications, 20(1-2), $82-102$.

Davis, J. W. (1978), “Epistle to Mark Moore on the infinite value of man”, research paper, University of Tennessee.

De Ruyter, K., Wetzels, M., Lemmink, J., and Mattsson, J. (1997), “The dynamics of the service delivery process: a value-based approach", International Journal of Research in Marketing, Vol. 14, No. 3, July, pp. 231-43.

Dellarocas, Ch. (2003), The Digitization of Word of Mouth: Promise and Challenges of Online Feedback Mechanisms, Management Science, 49 (October), 1407-1424.

Derks, D., Fischer, A. H. and Bos, E. E. R. (2008), The role of emotion in Computer Mediated Communication: A Review. Computers in Human Behaviour, 24(3), 766785.

Elliott, B. C. (1969), Item Homogeneity and Factorial Invariance for Normative and Ipsative Responses to the Hartman Value Inventory, Ph.D. Dissertation, University of Tennesee.

Fang, Y. (2014) Beyond the Credibility of Electronic Word of Mouth: Exploring eWOM Adoption on Social Networking Sites from Affective and Curiosity Perspectives, International Journal of Electronic Commerce, 18 (3), 67-101.

Gifford, A. (2002). Emotion and Self-Control. Journal of Economic Behavior and Organization, 49, 113-130.

Groeger, L., and Buttle, F. (2014), Word-of-mouth marketing influence on offline and online communications : evidence from case study research. Journal of Marketing Communications, 20(1-2), 21- 41.

Hanoch, Y. (2001). Neither an angel nor an ant: Emotion as an aid to bounded rationality. Journal of Economic Psychology, 23, 1-25.

Hartman, R., S. (1973), The Hartman Value Profile (HVP): Manual of Interpretation, Research Concepts, Muskegon, Michigan.

Hartman, R.,S. (1967), The Structure of Value: Foundations of Scientific Axiology. Southern Illinois University Press.

Hennig-Thurau, T., Gwinner, K.P., Walsh, G., Gremler, D.D., 2004. Electronic Word-ofMouth Via Consumer Opinion Platforms: What Motivates Consumers to Articulate Themselves on the Internet. Journal of Interactive Marketing 18 (1), 38-52. 
Herr, P.M., F.R. Kardes, and Kim, J. (1991), "Effects of Word-of-Mouth and ProductAttribute Information on Persuasion: An Accessibility-Diagnosticity Perspective." Journal of Consumer Research 17 (4) (March 1): 454-462.

Holbrook, M. B. (1996), "Special Session Summary Customer Value: a Framework For Analysis and Research", in NA - Advances in Consumer Research Volume 23, eds. Kim P. Corfman and John G. Lynch Jr., Provo, UT: Association for Consumer Research, Pages: 138-142.

Holzweber, M., Mattsson, J., and Standing, C. (2013), "Building Consumer Tribes on the Web by Electronic Word of Mouth", paper presented to RESER Annual Conference, Aix-en-Provence, 19-21 September, 2013.

Hornik, J., Satchi, R. S., Cesareo, L., \& Pastore, A. (2015). Information dissemination via electronic word-of-mouth: Good news travels fast, bad news travels faster!. Computers in Human Behavior, 45, 273-280.

Jaime A.,, B. Butler, L. Joyce, R. Kraut, K. Ling, C. Rosé, and Wang, X. (2006), Talk to Me: Foundations of Successful Individual-Group Interactions in Online Communities. In Proceedings of the SIGCHI conference on Human Factors in computing systems (CHI'06).

Karau, S.J., and Williams, K.D. (1994), Social loafing: A meta-analytic review and theoretical integration. Journal of Personality and Social Psychology, 65, 681-706.

Lemmink, J., and Mattsson, J. (1996), "Warmth during non-productive retail encounters: the hidden side of productivity", International Journal of Research in Marketing, Vol. 15, No. 5, pp. 505-517.

Lemmink, J., and Mattsson, J. (2002), “Employee behaviour, feelings of warmth and customer perception in service encounters", International Journal of Retail and Distribution Management, Vol. 30, No. 1, pp. 18-33.

Litvin, S W. Goldsmith, R. E. and Pan, B. (2008), "Electronic word of mouth in hospitality and tourism management", Tourism Management, Vol. 29, No. 3, pp. 458-468.

Lohman, J. S., (1968), The Professor's Influence on the Student's Capacity to Value, Ph. D. Dissertation, Boston University.

Ma, M., and Agarwal, R. (2007), Through a Glass Darkly: Information technology Design, Identity Verification, and Knowledge Contribution in Online Communities. Information Systems Research, 18(1), 42-67.

Markus, L. (1987), Toward a 'critical mass' theory of interactive media: Universal access, interdependence and diffusion," Communication Research, volume 14, pp. 491511.

Mattsson, J. (1990), Better Business by the ABC of Values, Studentlitteratur: Lund 
Meuter, M.L., D. Brown McCabe, and J.M. Curran (2013), "Electronic Word-of-Mouth Versus Interpersonal Word-of-Mouth: Are All Forms of Word-of-Mouth Equally Influential?", Services Marketing Quarterly 34 (3): 240-256.

Moore, M. A.(1973), "Can an Ethical theory be defended?" Unpublished PhD dissertation, University of Tennessee: Knoxville. of-mouth via consumer-opinion platforms: What motivates consumers to

Patterson, M. (1998), Direct marketing in post modernity: neo-tribes and direct communications, Marketing Intelligence \& Planning, Vol. 16 No. 1, 6-74.

Reichelt, J. (2013), “Einflussfaktoren der Bedeutung von Online Word-of-Mouth für Konsumenten." In Informationssuche und Online Word-of-Mouth, 105-144.

Reichheld, F.F. (2003), The one number you need. Harvard Business Review, December, 46-54.

Reynolds, M., Chris R. Brewin, C. R., \& Saxton, M. (2000). Emotional Disclosure in School Children. J. Child Psychol. Psychiat. Vol. 41, No. 2, pp. 151-159

Roed, J. (2003), Language learner behavior in a virtual environment. Computer Assisted Language Learning, 16(2/3), 155-172.

Rokeach, M. (1973), The Nature of Human Values, The Free Press, New York.

Roseman, I. J., Wiest, C., \& Swartz, T. S. (1994). Phenomenology, behaviors, and goals differentiate discrete emotional state. Psychological Review, 69, 379-399.

Rosenbaum-Elliott, R., L. Percy, and Pervan S. (2011), Strategic Brand Management. 2nd ed. OUP Oxford.

Saif, S. M., Zhu, X., Kiritchenko, S. \& Martin, J. (2014). Sentiment, emotion, purpose, and style in electoral tweets. Information Processing and Management, http://dx.doi.org/10.1016/i.ipm.2014.09.003

Söderlund, M. and Mattsson, J. (2011), Word-of-mouth is more than recommendations, paper presented to ANZMAC (Australian New Zeeland Marketing Academy) Annual Conference in Perth in 28 November- 1 December.

Stake, R.E. (1995), The Art of Case Study Research. Sage Publications.

Standing, C. and Kiniti, S. (2011), How Can Organizations Use Wikis for Innovation? Technovation, 31 (7), pp. 287-295.

Sun, J., Wang, G., Cheng, X. \& Fu, Y. (2014). Mining affective text to improve social media item recommendation. Information Processing and Management (2014), http://dx.doi.org/10.1016/j.ipm.2014.09.002 
Sussan, F. (2005), The Added Value of Online Word-of-Mouth (eWOM) to Advertising in New Product Adoption: An Empirical Analysis of the Movie Industry, unpublished PhD dissertation, The City University of New York.

Tan, E. S-H. (2008), "Entertainment Is Emotion: The Functional Architecture of the Entertainment Experience." Media Psychology 11 (1): 28-51.

Thelwall, M., Wilkinson, D. and Uppal, S. (2010), Data mining emotion in social network communication: Gender differences in MySpace. Journal of the American Society for Information Science and Technology, 61(1), 190-199.

Toder-Alon, A., F.F. Brunel, and Fournier, S. (2013), "Word-of-mouth Rhetorics in Social Media Talk", Journal of Marketing Communications. (Forthcoming).

Verhagen, T., Nauta, A., \& Feldberg, F. (2013). Negative online word-of-mouth: Behavioral indicator or emotional release?. Computers in Human Behavior,29(4), 1430-1440.

Walther, J. B., and D'Addario, K. P. (2001), "The impacts of emoticons on message interpretation in computer-mediated communication". Social Science Computer Review 19 (3): 323-345.

Willis, M. and Jones, C. (2012), Supporting Emotion Communication in Information Systems. 23rd Australasian Conference on Information System, Geelong, Australia.

Yin, D., Bond, S. D., and Zhang, H. (2014). Anxious or Angry? Effects of Discrete Emotions on the Perceived Helpfulness of Online Review. MIS Quarterly, 38(2), 539-560.

Yin, R.K. (2012), Case Study Research: Design and Methods. 5th ed. Sage Publications, Inc. Zeelenberg, M., Nelissen, R, M. A., Breugelmans, S. M. \& Pieters, R. (2008). On Emotion Specificity in Decision Making: Why Feeling is for Doing, Judgment and Decision Making, 3(1), 18-27.

Zhang, J., and Daugherty, T. (2009), “Third-Person Effect and Online Social Networking: Implications for Viral Marketing, Word-of-Mouth Brand Communications, and Consumer Behavior in User-Generated Context." American Journal of Business 24 (2): 53-63. 